\title{
Genetic structuring and differentiation of Echinococcus multilocularis in Slovakia assessed by sequencing and isoenzyme studies
}

\author{
V. ŠNÁBEL, M. MITERPÁKOVÁ, S. D'AMELIO ${ }^{1}$, M. BUSI ${ }^{1}$, D. BARTKOVÁ, L. TURČEKOVÁ, \\ C. MADDOX-HYTTEL ${ }^{2}$, P. SKUCE ${ }^{3}$, P. DUBINSKÝ
}

\begin{abstract}
Parasitological Institute, Slovak Academy of Sciences, Hlinkova 3, 04001 Košice, Slovakia; E-mail: snabel@saske.sk; ${ }^{1}$ Department of Sciences of Public Health, Parasitology Section, University of Rome „La Sapienza“, Piazzale Aldo Moro 5, 00185 Rome, Italy; ${ }^{2}$ Department of Veterinary Diagnostics and Research, Danish Institute for Food and Veterinary Research, Bülowsvej 27, DK-1790 Copenhagen V, Denmark; ${ }^{3}$ Moredun Research Institute, Pentlands Science Park, Bush Loan, Penicuik, Midlothian EH26 0PZ, Scotland, UK
\end{abstract}

\begin{abstract}
Summary
Nucleotide sequencing of the mitochondrial cytochrome $c$ oxidase subunit 1 (CO1) gene and isoenzyme analysis were used to survey the genetic variability in Echinococcus multilocularis populations from Slovakia. A sample of 12 isolates acquired from 10 different districts from red foxes exhibited identical sequences. Compared with the previously described E. multilocularis variants, one base substitution was consistently observed relative to the M1 variant (detected in China, Alaska, North America, Japan) and three base substitutions were recorded relative to the M2 variant (detected in Germany) in the CO1 fragment. These data, along with the recently gathered data from French isolates, are indicative of a genetically unique population occurring in Central and Western Europe. Electrophoretic examination of enzymes produced by 14 gene loci revealed intraspecific polymorphism only with the glucose-phosphate isomerase (two distinct patterns) and the mannosephosphate isomerase (four genotypes composed of three alleles) enzyme systems. To allow a fast species differenttiation of E. multilocularis and E. granulosus (specifically, the G7 genotype occurring in Slovakia), discriminative electrophoretic characters between the species were obtained by isoenzyme analysis. Fixed genetic differences between the species were detected in the glucose-phosphate isomerase, esterase and aldolase systems, and partial differences were detected in four additional systems.
\end{abstract}

Key words: Echinococcus multilocularis; polymorphism; DNA; isoenzymes; Slovakia

\section{Introduction}

Human alveolar echinococcosis is caused by the larval stage of the small endoparasitic tapeworm Echinococcus multilocularis. The parasite is of great public health concern as it may cause severe and even lethal disease in humans.
Recent surveys in Europe have extended the known geographical distribution of $E$. multilocularis to a contiguous area stretching from south-central Europe (northern Italy, central France) to northern parts of Europe covering Denmark, Lithuania and Estonia (Gawor et al., 2004; Svobodová et al., 2004; Moks et al., 2005; Duscher et al., 2006; Romig et al., 2006; Saeed et al., 2006). In Slovakia, the parasite was detected for the first time in 1999 (Dubinský et al., 1999), and is abundant especially in the northern parts of the country, with an overall prevalence in red foxes as high as $37.6 \%$ in 2005 (Miterpáková, personal communication). Since 2000, six cases of autochthonous alveolar echinococcosis in humans have been reported in the Žilina, Prešov and Banská Bystrica counties in northern and central parts of Slovakia where high occurrences of $E$. multilocularis in foxes were continuously found (Kinčeková et al., 2002, 2004). Coupled to its growing epidemiological importance are new endemic areas of the parasite in western and southern parts of Slovakia as well as the increasing presence of foxes in urban areas (Miterpáková et al., 2006). The development of new methods to enhance the knowledge of parasite transmission patterns is therefore of great interest.

In contrast to the Echinococcus granulosus complex which comprises several designated strains and species, a high degree of genetic uniformity is characteristic for $E$. multilocularis. Although some data pertaining to differences in morphology, virulence, antigen expression and developmental characteristics have been described among $E$. multilocularis isolates, only a limited genetic variation has been detected within the species (Bart et al., 2003). Isoenzyme methods have proven useful particularly in investigations of population structures and breeding systems of parasites (Andrews \& Chilton, 1999). To our knowledge, isoenzyme analysis of the E. multilocularis genetic composition has only been employed in a study of McManus and Smyth 
(1979) who compared enzyme profiles of E. granulosus (sheep and horse strains) and E. multilocularis (isolates from cotton rats). No attempts have been made to investigate the intraspecific allozyme-based variability of species. For assessing genetic variants and the nature of reproduction in Echinococcus parasites, mitochondrial proteincoding genes have often been targeted due to their relatively rapid rate of evolution and high degree of conservation within lines (e.g., Bowles et al., 1992; Haag et al., 1999; Nakao et al., 2003)

The current study was designed to characterize Slovak tapeworms according to previously described variants and to further analyze the genetic diversity of E. multilocularis at the regional and local levels in Slovakia by means of isoenzyme (nuclear genes) and DNA (mitochondrial gene) methods. In addition, distinguishing electrophoretic characters for E. granulosus (pig strain) and E. multilocularis, were provided in the study, enabling a fast species diagnosis.

\section{Material and Methods}

Red foxes infected with $E$. multilocularis $(E m)$ were captured in 19 districts of Slovakia. Adult worms of $E m$ were collected from the small intestines of naturally infected red foxes by a sedimentation and counting technique (SCT) (Rausch et al., 1990). Parasites were washed in phosphatebuffered saline (PBS) ( $\mathrm{pH} 7.3$ ), and isolates were subsequently either fixed in $70 \%$ ethanol for further DNA analyses in cases of low worm burdens $(10-100$ worms $)$, or frozen at $-72^{\circ} \mathrm{C}$ for isoenzyme analyses when higher worm burdens were found. As reference material, larval stages (protoscolices) of E. granulosus ( $E g$ ) were obtained from hydatid cysts from a Slovak pig.

DNA extraction was performed by standard procedures using a Wizard Genomic DNA purification kit (Promega). A fragment of the mitochondrial cytochrome $c$ oxidase subunit 1 (CO1) gene was amplified using primers described by Bowles et al. (1992), formerly designed for Fasciola hepatica (Garey \& Wolstenholme, 1989). The primers had the following nucleotide composition: Forward - 5'TTT TTTGGGCATCCTGAGGTTTAT3'; Reverse - 5'TAAAG AAAGAACATAATGAAAATG-3'. PCR reactions were performed in a total volume of $50 \mu$ under the following cycling conditions: initial denaturation step $94^{\circ} \mathrm{C}$ for $5 \mathrm{~min}$ followed by 35 cycles, $94^{\circ} \mathrm{C}$ for $30 \mathrm{~s}, 55^{\circ} \mathrm{C}$ for $60 \mathrm{~s}$, and $72^{\circ} \mathrm{C}$ for $60 \mathrm{~s}$. PCR products were electrophoresed through $1.5 \%$ agarose gels and detected by ethidium bromide staining. Amplicons were purified using the Geneclean II Kit (Bio101, Inc.), directly sequenced using the BigDye Terminator Cycle Sequencing Kit (Applied Biosystems) on an ABI Prism 3700 DNA Analyzer (Applied Biosystems). Obtained sequences were aligned with the published sequences of $\mathrm{CO} 1$ for Echinococcus parasites using CLUSTAL W (Thompson et al., 1994).

For isoenzyme analysis, 112 samples $(200-1000$ adults of $\mathrm{Em}$; up to $0.5 \mathrm{~g}$ of $\mathrm{Eg}$ protoscolices for each isolate) were crushed in an equal volume of distilled water. Homoge- nates were centrifuged at $10 \mathrm{~min}$ at $12000 \mathrm{~g}$ and supernatants were further analysed by an isoelectrofocusing (IEF) technique using the Multiphor II Electrophoresis System equipped with a MultiTemp III Thermostatic Circulator (Amersham Biosciences). Enzyme extracts were applied in a volume of $15 \mu \mathrm{l}$ onto Ampholine PAG plates (Amersham Biosciences) with $\mathrm{pH}$ ranges of $3.5-9.5$ and $4.0-6.5$ at 1 $\mathrm{cm}$ from the cathode and subjected to electrophoresis for $1.5 \mathrm{~h}$ (broad $\mathrm{pH}$ range) or for $2.5 \mathrm{~h}$ (narrow $\mathrm{pH}$ range). Following electrophoresis, gels were stained for various enzyme systems using methods modified from Murphy et al. (1996) and Turčeková et al. (2003), in consideration of recommendations of McManus and Smyth (1979) regarding Echinococcus parasites (when identical enzymes were tested). Histochemical reagents were applied in the $1.2 \%$ agar overlay, except esterase (EST) and glutamate-oxaloacetate transaminase (GOT) enzymes.

Soluble parasite extracts yielded good resolution and sufficient staining intensity in the following systems: adenylate kinase (AK, EC 2.7.4.3), aldolase (ALD, EC 4.1.2.13), esterase (EST, EC 3.1.1.1), fumarate hydratase (FUMH, EC 4.2.1.2), glycerophosphate dehydrogenase (GPD, EC 1.1.1. 8), glucose-phosphate isomerase (GPI, EC 5.3.1.9), glutamate-oxaloacetate transaminase (GOT, EC 2.6.1.1), hydroxybutyrate dehydrogenase (HBDH, EC 1.1.1.30), malate dehydrogenase (MDH, EC 1.1.1.37), mannose-phosphate isomerase (MPI, EC 5.3.1.8), peptidase A with leucine-tyrosine substrate (PEP-A, EC 3.4.11.1), peptidase D with phenylalanine-proline substrate (PEP-D; EC 3.4.13. 9), and phosphoglucomutase (PGM, EC 5.4.2.2). At each locus, presumed isoenzymes were labelled numerically, according to the mobility relative to that of the most common signal (which was assigned a mobility value of 100).

\section{Results}

DNA analyses

Partial sequences (354 bp) were obtained from E. multilocularis $(E m)$ and E. granulosus $(E g)$ for the CO1 gene directly from the PCR products and were aligned with the sequences previously detected for the M1 and M2 variants of $\mathrm{Em}$. Of the sequenced $12 \mathrm{Em}$ isolates sequenced, 5 originated from Central Slovakia, 4 from Western Slovakia and 3 from Eastern Slovakia, with 11 districts involved as a capturing site of respective red foxes. All $\mathrm{Em}$ isolates possessed fully identical COI sequences, differing at one $(0.3 \%)$ nucleotide site (position $65 ; \mathrm{A}-\mathrm{G}$ transition) from the M1 variant and at three $(0.8 \%)$ sites (positions 3, 43,

Table 1. Variable sites of E. multilocularis within the examined part of the CO1 gene

\begin{tabular}{lccc}
\hline Nucleotide position & $\# 3$ & $\# 43$ & $\# 65$ \\
\hline Slovak isolates (DQ013305) & A & C & A \\
French isolates* & A & C & A \\
M1 variant (M84668) & A & C & G \\
M2 variant (M84669) & G & T & G \\
\hline
\end{tabular}

* published by Boucher et al. (2005) 
and 65) from the M2 variant (Table 1). All detected substitutions corresponded to transitions-type mutations. In the analyzed fragment, Slovak isolates shared all sequences with the two French isolates from wild boar published by Boucher et al. (2005). A representative sequence of the Em in Slovakia was deposited in GenBank under the accession no. DQ013305. Compared to the Eg isolate (confirmed as bearing the G7 genotype), the examined $E m$ isolates differed at $9.9 \%$ of positions.

\section{Isoenzyme analysis}

Among the 13 enzymes examined for the $E m$ isolates, one major invariant band of activity was detected in ALD, EST, GOT, FUMH, PEP-A and PEP-D enzymes. For ALD and FUMH, a prominent band was in most cases accompanied by fainter bands attributable to secondary isoenzymes. Three clustered zones of activity were seen with $\mathrm{HBDH}$ in the anodal zone of the gel. For GPD, double- or threebanded phenotypes with faint signals were found. The appearance of a third band in this enzyme was presumed to be associated with differences in enzyme activity among samples rather than with genetically induced variation. AK was characterized by an intense band located behind the start and two faster bands being more distant from each other, but remaining at the cathodal end of the gel. $\mathrm{MDH}$ produced three major isoenzymes placed across a broader zone of gel, followed by secondary isoenzymes, but invariant between the Em samples. PGM generated three-banded patterns, in which the anodal electromorph was less active compared with the two slower electromorphs. Genetic polymorphism in Em samples from Slovakia was consistently detected only in two enzyme systems, MPI and GPI. Variation in MPI was interpretable in a genetic context, allowing us to establish an allelic profile for each sample. Double-banded phenotypes in heterozygotes corresponded to monomeric enzyme systems (Fig. 1). Three alleles attributable to four genotypes were recorded in the examined sample. The homozygous genotype 100/100 was expressed in 4 isolates, 2 samples of which originated from the Prešov district (Eastern Slovakia, ES), 1 sample from Snina (ES) and 1 sample from Liptovský Mikuláš (Central Slovakia, CS). In 1 isolate, a presumed homozygote 102/102 was manifested (Prešov, ES). Heterozygous genotypes were those of 100/102, detected in 2 isolates (Prešov, Spišská Nová Ves, both ES), and 100/103 being manifested in 1 isolate (Sabinov, ES). In addition, a three-banded pattern resolved in 1 isolate acquired from a fox shot in the Prešov district (ES) was indicative of multiple infection with more than one genotype. Within scored isolates, the allele 100 was predominant (frequency of 0.69), the allele 102 had a frequency of 0.25 , and the rare allele 103 was registered only in the heterozygous form and in a multiple infection (frequency of 0.06). For this enzyme, only 9 samples were adequately resolved due to a weaker MPI activity expressed in the $E m$ samples. Sufficient signal intensity was obtained only from isolates containing at least $600-$ 700 specimens derived from foxes stored for a shorter period $(1-2$ weeks) prior to dissection. In GPI, 2 distinct

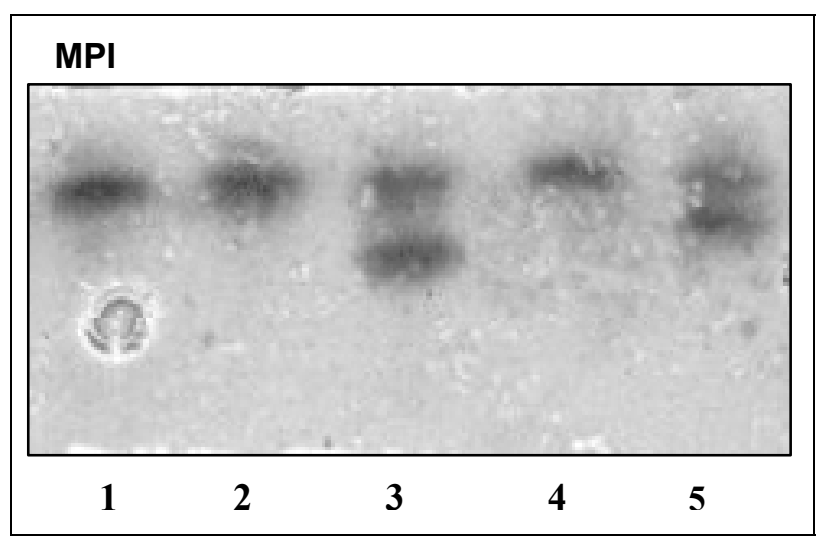

Fig. 1. Zymogram of mannose-phosphate isomerase (MPI) for $E$. multilocularis isolates from red foxes in Slovakia. Lane 1, genotype 100/100 (Prešov, ES); lane 2, genotype 100/100 (Snina, ES); lane 3, genotype 100/103 (Prešov, ES); lane 4, genotype 100/100 (Liptovský Mikuláš, CS); lane 5, genotype 100/102 (Spišská Nová Ves, ES)

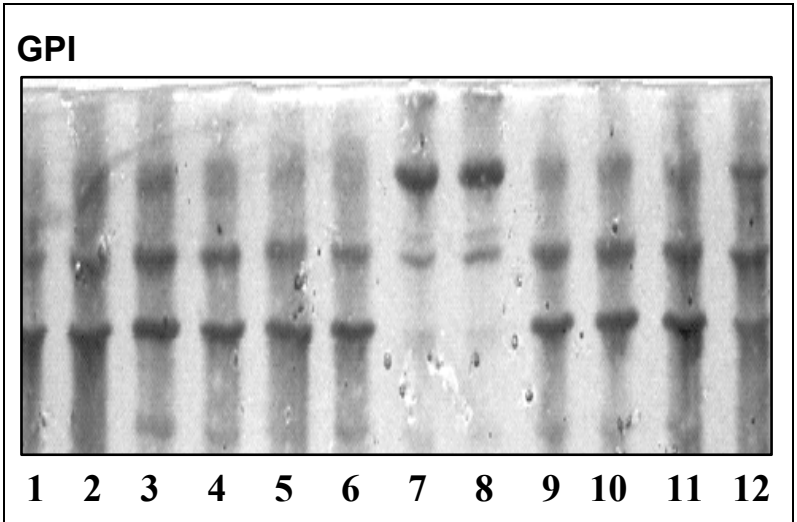

Fig. 2. Zymogram of glucose-phosphate isomerase (GPI) for $E$. multilocularis isolates from red foxes in Slovakia. Lanes 1, 2, isolate from Zvolen (CS); lane 3, Nitra (WS); lanes 4, 5, Košice (ES); lane 6, Čadca (CS); lane 7, Levice (WS); lanes 8, 9, Prešov (ES); lanes 10, 11, Dolný Kubín (CS); lane 12, Trenčín (WS)

profiles were detected in $E m$ samples under examination (Fig. 2). Triple-banded phenotypes were characteristic for both profiles, with two bands shared between phenotypes, and one band found as unique in both cases. A dominant profile 1 was ascertained in 17 isolates. The two slower isoenzymes were of stronger intensity and an additional anodal isoenzyme was less intense. Of the three major bands recorded in profile 2 (samples Nos 7, 8; Fig. 2), one band has migrated more anodally compared with profile 1 . In addition, a central band was prominent and peripheral bands were of weaker intensity in profile 2 . This phenotype was recorded in 3 isolates, originating from Čadca (CS), Bardejov (ES), and Levice (Western Slovakia, WS). Sub-bands backward (cathodal) of major isoenzymes have occasionally appeared in both profiles.

When comparing the Em and Eg (pig isolates) electrophoretic profiles, identical patterns for major staining bands 
were found with the GOT, FUMH, PEP-A and PEP-D enzymes. The main electromorphs presumed to be associated with major isoenzymes are given in Table 2. Partial differrences between the two species were recorded in $\mathrm{AK}$, PGM, GPI and MPI. For PGM the two bands were shared between $E m$ and $E g$, and a third band was unique, in $E g$ located more cathodally. In AK, one of the weaker signals was absent in $E m$ relative to $E g$. In MPI, apart from the two common bands between the species under survey, a dominant allele in $E m$ (100) was not found in $E g$. No activity was seen in HBDH and GPD in $E g$ (unlike $E m$ ) in the examined isolates.

Presumed fixed differences (when no signal was common)

Table 2. Major isoenzymes detected in E. multilocularis and E. granulosus (G7)

\begin{tabular}{|c|c|c|}
\hline Enzyme & EM & EG \\
\hline \multirow[t]{3}{*}{ MPI } & 100 & 102 \\
\hline & 102 & 103 \\
\hline & 103 & \\
\hline \multirow[t]{6}{*}{ GPI } & 97 & 99 \\
\hline & 100 & 102 \\
\hline & 103 & 105 \\
\hline & 100 & \\
\hline & 103 & \\
\hline & 106 & \\
\hline \multirow[t]{5}{*}{ EST } & 101 & 100 \\
\hline & & 102 \\
\hline & & 105 \\
\hline & & 107 \\
\hline & & 111 \\
\hline ALD & 100 & 80 \\
\hline \multirow[t]{3}{*}{ PGM } & 100 & 98 \\
\hline & 102 & 100 \\
\hline & 104 & 102 \\
\hline \multirow[t]{3}{*}{$\mathrm{MDH}$} & 100 & 97 \\
\hline & 103 & 100 \\
\hline & 106 & 103 \\
\hline \multirow[t]{3}{*}{ AK } & 100 & 100 \\
\hline & 109 & 105 \\
\hline & & 109 \\
\hline GOT & 100 & 100 \\
\hline FUMH & 100 & 100 \\
\hline PEP-A & 100 & 100 \\
\hline PEP-D & 100 & 100 \\
\hline \multirow[t]{3}{*}{ GPD } & 100 & - \\
\hline & 101 & \\
\hline & 102 & \\
\hline \multirow[t]{3}{*}{ HBDH } & 100 & - \\
\hline & 101 & \\
\hline & 103 & \\
\hline
\end{tabular}

EM, E. multilocularis; EG, E. granulosus, G7 between $E g$ and $E m$ were indicated with the GPI, EST and ALD systems. In GPI, the positions of major isoenzymes in both profiles (mobility values of $97,100,103,106$ ) for $E m$ differed slightly relative to $E g(99,102,105)$. In EST, the two loci seemed to be responsible for patterns observed in $E g$ for which four bands were displayed at the Est-2 locus, and one anodal band was detected at Est-1. In contrast, only one differently located band of activity was seen in $E m$ at Est-2 compared with the Eg electromorphs. For ALD, a diffuse band in the cathodal zone was expressed in $E g$, whereas $E m$ displayed a faint band resolved closer to the anodal end.

\section{Discussion}

The present study revealed a slight DNA variation among E. multilocularis isolates from Slovakia and previously described species variants by analysis of fragments of the mitochondrial genes. A low degree of polymorphism of the Slovak E. multilocularis population was detected by isoenzyme analysis, with the two enzymes exhibiting variable profiles. Major factors that contribute to the low genetic variation of E. multilocularis (compared with E. granulosus organisms) are likely attributable to the facts that the species is phylogenetically young and is restricted to the conserved host spectrum involving mobile major definitive and intermediate hosts (foxes, rodents), which provides an extensive gene flow within parasite populations.

Limited sample sizes, low detected variation and/or sensitivity of the employed methods have often precluded inferences concerning epidemiological significance of genetic data gathered for E. multilocularis. In previous studies, the most genetically differentiated population within species seems to be that originating from St. Lawrence Island in the Bering Sea between Alaska and Siberia (Haag et al., 1997; Rinder et al., 1997). These authors presented data from analyses of non-coding $\mathrm{Hbx} 2$ and coding $18 \mathrm{~S}$ regions, which revealed consistent differences between samples from this island compared to samples from Europe, Japan, Canada, and continental Alaska.

Analyses of segments of mitochondrial genes for cytochrome $c$ oxidase subunit 1 (CO1) and NADH dehydrogenase subunit 1 (ND1) have been successfully applied to identify a given Echinococcus isolate as belonging to a particular genotypic/species group (Bowles \& McManus, 1993; Mc Manus \& Thompson, 2003). For E. multilocularis, Bowles et al. (1992) and Bowles and McManus (1993) formerly detected differences in the two nucleotides between human isolates from China, Alaska and North America (the group designated as the M1 variant) and isolates from naturally infected rodents from Germany (the M2 variant) in partial CO1 and ND1 genes. Later, Okamoto et al. (1995) identified $\mathrm{CO} 1$ sequences fully corresponding to the M1 variant in five isolates from Japan and one isolate from St. Lawrence Island. In our study, Slovak isolates sequenced in the CO1 gene differed at one nucleotide base from the M1 variant (the $0.3 \%$ difference value) and in three bases from the M2 variant (the $0.8 \%$ difference). The M2 variant de- 
tected in a German rodent isolate by Bowles et al. (1992) had likely occurred only over a limited territory and had not been spread into a broader region of central Europe. Consistent differences observed in the examined Slovak sample, associated with one/three bases compared with the remaining isolates tested before at the $\mathrm{CO} 1$ locus, are suggestive of a genetically unique population circulating in the region. Furthermore, the identical sequences of the Slovak isolates and the French isolates examined by Boucher et al. (2005) indicate that this variant is present in a larger territory of west-central Europe, and is distinguishable from the common M1 variant of E. multilocularis confirmed in the western part of Asia and North America. This corresponds to findings in neighbouring Poland by Kedra et al. (2000) who obtained unique ND1 sequences of four Polish isolates that were more similar to the M1 variant $(0.6 \%$ difference) than to the M2 variant (1.1\% difference).

To uncover genetically linked polymorphism, microsatellite analysis provides a promising approach to circumvent the high degree of genetic homogeneity in E. multilocularis (Bart et al., 2003). By examining a microsatellite upstream of the U1 snRNA gene complex, three different profiles were detected in E. multilocularis; one pattern was assigned to isolates from France, Switzerland, Germany and Alaska; the second to Japan and Alaska, and the third to Montana and Alaska (Bretagne et al., 1996). Given these data, Rinder et al. (1997) pointed out the risk of overdiscrimination with such a highly resolving technique that may skew the view about $E$. multilocularis genetic structuring if not interpreted with caution. Later, two microsatellite loci from a genomic library of E. multilocularis were isolated which revealed a population-level polymorphism in samples from Hokkaido (Japan), with minor heterozygosities $(10.6 \%$ and $7.7 \%$ ) determined at both loci (Nakao et al., 2003). Based on the allelic composition observed, a few cases of multiple infections of foxes were also documented in the above report. In the current study, one case of mixed infection was indicated (in a fox captured in Prešov district) on the basis of the MPI pattern displaying three alleles in one isolate. It is presumed that ingestion by foxes of several infected rodents commonly occurs but that the low genetic diversity of species has limited the possibilities to detect such multiple infections.

Isoelectric focusing (IEF) is useful especially for typing by isoenzyme analysis when slight differences between electromorphs cannot be clearly seen with standard electrophoretic techniques such as starch or cellulose acetate electrophoreses (Allsopp et al., 1983; Piarroux et al., 1994). The drawback of IEF is the propensity to detect post-genetic modifications that may give rise to multiple forms of enzymes due to factors such as side-chain cleavage, conformational alterations or aggregations, which can make genetic interpretation difficult with some systems. A few of the enzymes herein studied gave discrete resolution of banding clusters, occasionally with slightly variant profiles between $E$. multilocularis isolates linked to additional signals (GPD, ALD, FUMH, HBDH). This could be ascribed to variation between activity and quality of samples, with displayed bands most likely representing products of a single identical allele. Although the patterns were not absolutely invariant with these enzymes, their identity was readily discernible. Storage conditions were also taken into account in interpretation of profiles given that secondary isoenzymes are prone to be formed in the course of longterm storage (Richardson et al., 1986).

The two enzyme loci that unambiguously produced polymorphic patterns in the E. multilocularis samples from Slovakia were mannose-phosphate isomerase (MPI) and glucose-phosphate isomerase (GPI). Predicted genetic basis of the observed variation has been consistently seen with MPI system. Five of the 9 positive samples resolved by MPI originated from the Prešov district in Eastern Slovakia, where the majority of the foxes with heavier worm burdens had been collected (along with the Žilina county in Central Slovakia at average 1870 specimens/fox), which enabled detection with the generally weaker MPI activity. No outputs regarding Hardy-Weinberg equilibrium at the locality could be estimated due to the small sample size being scored. However, detection of three presumed heterozygotes indicates that occasional outcrossing does occur in tapeworms transmitting in the region. This is congruent with the microsatellite-based evidence of heterozygosity seen in the E. multilocularis population on Hokkaido (Nakao et al., 2003). For the polymorphic GPI enzyme, the allelic composition could not be inferred by the employed technique and the resulting patterns were thereby scored by the zymodeme approach according to Andrews and Chilton (1999). In addition to the profile 1 (manifested by 17 isolates), the unique profile 2 was found in three isolates originating from different parts of the Slovak region (northeastern, north-central and south-western part of Slovakia). No geographic delimitation was thus recorded for this variant, which could be accounted for by the long-distance movement of foxes implying unstable foci of the parasite.

Thirteen enzymes encoded by 14 putative gene loci were surveyed in the present study. About $8.3 \%$ of nucleotide substitutions are detected by enzyme electrophoresis (Nei, 1987). Considering 1200 nucleotides in the coding region of an average structural gene, electrophoresis should examine approx. 100 nucleotides per enzyme locus (Lymbery \& Thompson, 1991). As 14 loci correspond to studying approx. 1400 nucleotides and only two loci were polymorphic in the investigated sample, the work provides further support to the view of remarkable genetic uniformity in $E$. multilocularis. At least six isolates were screened for every enzyme system in the study.

The fast confirmation of species identity by electrophoretic differentiation of E. multilocularis and E. granulosus is particularly useful when juvenile stages of species (often not distinguishable morphologically) are recovered from the common host species in sufficient amount, and in case of confirmation of mixed infections. Substantial variation was detected between these taxa (for E. granulosus represented by the G7 genotype that is solely transmitted in central-eastern Europe) by isoenzyme analysis, using which four enzyme systems exhibited partial differences between 
the species and three systems shared no common signal for the two species. The fully diagnostic enzymes were those of glucose-phosphate isomerase (GPI), esterase (EST) and al-dolase (ALD). For diagnostic purposes, GPI appeared to be the most convenient system; with EST and ALD faint bands were resolved in Em and some isolates in both species had not manifested a detectable enzyme activity.

Sheep and horse genotypes of E. granulosus, now regarded as two separate species E. granulosus sensu stricto and $E$. equinus, respectively (Thompson \& McManus, 2002; Romig et al., 2006), were previously compared with $E$. multilocularis by the IEF technique in British isolates (McManus \& Smyth, 1979). Among the tested enzymes, five systems were identical with those used in the current study (GPI, PGM, MDH, AK, GPD). Similar banding patterns for $E m$ were documented in both studies, partially except AK for which some anodal bands were not detected with the Slovak isolates. Likewise, GPD gave no well-defined E. granulosus band in our work. Profiles of GPI and ALD similarly varied between the species. In British isolates a fixed interspecific difference was recorded also with lactate dehydrogenase (LDH). Instead, EST found to be diagnostic in this study, was not examined by McManus and Smyth (1979).

The present results provide a foundation for further genetic analyses of E. multilocularis in western and central Europe, particularly by DNA sequencing and affiliated approaches. To track a distribution of species variants herein detected by $\mathrm{CO} 1$ analysis, the inclusion of more variable genetic characters is stressed along with the recovery of isolates covering wider contiguous area in Europe. Deeper investigations into the putative role of the genetic diversity in E. multilocularis may assist in better understanding of the transmission of alveolar echinococcosis and evolution of the species concerned.

\section{Acknowledgements}

This work was supported by grants of the Slovak-Italian Science and Technology Cooperation for 2004-2007 (No. 08), the Slovak Grant Agency VEGA (No. 2/4179/26), and the Slovak Research and Development Agency (contract No. APVV-51-027605). We would like to thank to L. Bazanová, F. Lombardo and A. Lanfrancotti for their help in experiments and collection of parasite material.

\section{References}

Allsopp, B. A. (1983): Isoelectric focusing in agarose: a highly discriminatory method for the detection of enzyme heterogeneity. Ann. Trop. Med. Parasitol., 77: 169 - 173

Andrews, R. H., Chilton, N. B. (1999): Multilocus enzyme electrophoresis: a valuable technique for providing answers to problems in parasite systematics. Int. J. Parasitol., 29: $213-253$

Bart, J. M., Breyer, I., Gottstein, B., Romig, T., PiarROUX, R. (2003): Development of molecular tools to explore genetic diversity in Echinococcus multilocularis.
Helminthologia, 40: $117-121$

Boucher, J. M., Hanosset, R., Augot, D., Bart, J. M., Morand, M., PAIRrouX, R., POZET-Bouhier, F., LOSSON, B., Cliquet, F. (2005): Detection of Echinococcus multilocularis in wild boars in France using PCR techniques against larval form. Vet. Parasitol., 129: 259 - 266

Bowles, J., Blair, D., McManus, D. P. (1992): Genetic variants within the genus Echinococcus identified by mitochondrial DNA sequencing. Mol. Biochem. Parasitol., 54: $165-174$

Bowles, J., MCMAnus, D. P. (1993): NADH dehydrogenase 1 gene sequences compared for species and strains of the genus Echinococcus. Int. J. Parasitol., 23: 969 - 972

Bretagne, S., Assouline, B., Vidaud, D., Houin, R., VIDAUD, M. (1996): Echinococcus multilocularis: microsatellite polymorphism in U1 snRNA genes. Exp. Parasitol., 82: $324-328$

DUBINSKÝ, P., SVOBOdOVÁ, V., TURČEKOVÁ, L., LiterÁK, I., KolÁŘOVÁ, L., ReITEROVÁ, K., KolÁŘOVÁ, L., KLIMEŠ, J., MrLÍK, V. (1999): Echinococcus multilocularis in Slovak Republic: the first record in red foxes (Vulpes vulpes). Helminthologia, 36: $105-110$

Duscher, G., Pleydell, D., Prosl, H., JoAchim, A. (2006): Echinococcus multilocularis in Austrian foxes from 1991 until 2004. J. Vet. Med. B, 53: $138-144$

Garey, J. R., Wolstenholme, D. R. (1989): Platyhelminth mitochondrial DNA: evidence for early evolutionary origin of a tRNA ${ }^{\mathrm{ser}} \mathrm{AGN}$ that contains a dihydrouridine arm replacement loop, and of serine-specifying AGA and AGG codons. J. Mol. Evol., 28: 374 - 387

Gawor, J., Malczewski, A., Stefaniak, J., NAHORSki, W., PAUl, M., KACPRZAK, E., MYJAK, P. (2004): Risk of alveococcosis for humans in Poland. Przegl. Epidemiol., 58: $459-465$

HaAg, K. L., Araujo, A. M., Gottstein, B., Siles-LuCAS, M., ThOMPSON, R. C. A, ZAHA, A. (1999): Breeding system in Echinococcus granulosus (Cestoda; Taeniidae): selfing or outcrossing? Parasitology, 118: 63 - 71

HaAG, K. L., Zaha, A., Araujo, A. M., Gottstein, B. (1997): Reduced genetic variability within coding and noncoding regions of the Echinococcus multilocularis genome. Parasitology, 115: Part 5, 521 - 529

Kedra, A. H., ŚWIDERSKi, Z., TKACH, V. V., Rocki, B., PAWLOWSKI, J., PAWLOWSKI, Z. (2000): Variability within NADH dehydrogenase sequences of Echinococcus multilocularis. Acta Parasitol., 45: 353 - 355

KinČEKOVÁ, J., MiterpákovÁ, M., SzIlÁgYovÁ, M., HudÁČKOVÁ, J., AuER, H., DubinskÝ, P. (2004): Human alveolar echinococcosis in the Slovak Republic. In XXIst International Congress of Hydatidology, 16 - 21 August 2004, Nairobi, Kenya. Int. Arch. Hydatid., 35: 186

Kinčeková, J., ReiterovÁ, K., DubinskÝ, P., SZILÁGIYOVÁ, M., Johanes, R., GotTAs, M. (2002): A second case of human autochthonous alveolar echinococcosis in the Slovak Republic. Helminthologia, 39: 193 - 196

LyMBery, A. J., ThOMPson, R. C. A. (1991): Points in question: genetic diversity in Echinococcus granulosus - a reply to McManus. Int. J. Parasitol., 21: 153 - 154 
McManus, D. P., SMYTH, J. D. (1979): Isoelectric focusing of some enzymes from Echinococcus granulosus (horse and sheep strain) and E. multilocularis. T. Roy. Soc. Trop. Med. H., 3: $259-265$

McManus, D. P., Thompson, R. C. A. (2003): Molecular epidemiology of cystic echinococcosis. Parasitology, 27: $37-51$

MiterpákovÁ, M., AntolovÁ, D., ŠevČíKovÁ, Z., Stanko, M., Dinkel, A., GAŠPAR, V., DubinskÝ, P. (2006): Echinococcus multilocularis in musk rat (Ondatra zibethicus): the first finding of the parasite in naturally infected rodent in the Slovak Republic. Helminthologia, 43: $76-80$

Moks, E., SAarma, U., VAldman, H. (2005): Echinococcus multilocularis in Estonia. Emerg. Infect. Dis., 11: 1973 $-1974$

Murphy, R. W., Sites, JR. J. W., Buth, D. G., Haufler, C. H. (1996): Proteins: isozyme electrophoresis. In HILLIS, D. M. and MoRITZ, C. (Eds): Molecular Systematics, $2^{\text {nd }}$ ed., Sinauer Assoc. Inc., Sunderland, pp. $51-120$

NAKAO, M., SAKO, Y., ITO, A. (2003): Isolation of polymorphic microsatellite loci from the tapeworm Echinococcus multilocularis. Infect. Genet. Evol., 3: 159- 163

NEI, M. (1987): Molecular evolutionary genetics. Columbia University Press, New York

OKAmoto, M., Bessho, Y., KamiYa, M., Kurosawa, T., HORIL, T. (1995): Phylogenetic relationships within Taenia taeniaeformis variants and other taeniid cestodes inferred from the nucleotide sequences of the cytochrome $c$ oxidase subunit 1 gene. Parasitol. Res., 81: $451-458$

Piarroux, R., Trouvé, V., Pratlong, F., Martini, A., LAMBERT, M., RIOUX, J. A. (1994): The use of isoelectric focusing on polyacrylamide gel for the enzymatic analyses of "Old World" Leishmania species. T Roy Soc Trop Med.,
88: $475-478$

RAUSCH, R. L., FAy, F. H., Williamson, F. S. L. (1990): The ecology of Echinococcus multilocularis (Cestoda: Taeniidae) on St. Lawrence Island, Alaska. II. Helminth populations in the definitive hosts. Ann. Parasitol. Hum. Comp., 65: 131 - 140

Richardson, B. J., BAVERstock, P., AdAMs, M. (1986): Allozyme electrophoresis: a handbook for animal systematics and evolution. Academic Press, Sydney

Rinder, H., Rausch, R. L., TAKAhashi, H., KoPP, H., THOMSCHKE, A., LÖSCHER, T. (1997): Limited range of genetic variation in Echinococcus multilocularis. J. Parasitol., 83: 1045 - 1050

Romig, T., Dinkel, A., Mackenstedt, T. (2006): The present situation of echinococcosis in Europe. Parasitol. Int., 55: $197-191$

Saeed, I. S., MaddoX-Hyttel, C., Monrad, J., Kapel, C. M. O. (2006): Helminths of red foxes (Vulpes vulpes) in Denmark. Vet. Parasitol., 139:168 - 179

SvoBodovÁ, V., LeNSKÁ, B. (2004): Prevalence of Echinococcus multilocularis in out door cats in West Bohemia (Czech Republic). Helminthologia, 41: 221 - 222

Thompson, J. D., Higgins, T., GiBson, T. J. (1994): Clustal W: improving the sensitivity of progressive multiple sequence alignment through sequence weighting, positionspecial gap penalties and weight matrix choice. Nucleic Acids Res., 22: 4673 - 4690

ThOMPSON, R. C. A., MCMANUS, D. P. (2002): Towards a taxonomic revision of the genus Echinococcus. Trends Parasitol., 18: $452-457$

TurčEKovÁ, L., ŠnÁBel, V., D'Amelio, S., Busi, M., DUBINSKÝ, P. (2003): Morphological and genetic characterization of Echinococcus granulosus in the Slovak Republic. Acta Trop., 85: 223 - 229 